\title{
Trends of Ordering Hypercoagulability Work-Up at an Academic Medical Center
}

\author{
Marjan Alidoost \\ Gabriella A Conte \\ Varsha Gupta \\ Swapnil Patel \\ Ishan Patel \\ Mohammed Shariff \\ Shreya Gor \\ Michael J Levitt \\ Arif Asif \\ Mohammad A Hossain
}

Department of Medicine, Jersey Shore University Medical Center, Hackensack Meridian Health, Neptune, New Jersey, 07753, USA
Correspondence: Gabriella A Conte Chief Resident, Internal Medicine Residency Program, Department of Medicine, Jersey Shore University Medical Center, Hackensack-Meridian Health, Neptune, NJ, 07753, USA

Tel + I 20l-446-46| I

Email gabriella.

conte@hackensackmeridian.org
Background: Venous thromboembolism is a significant clinical event, with an annual incidence of 1-2 per 1000 population. Risk factors include recent surgery, prolonged immobility, oral contraceptive use, and active cancer. Inherited risks include protein $\mathrm{C}$ and $\mathrm{S}$ deficiencies, antithrombin deficiency, factor $\mathrm{V}$ Leiden mutation and prothrombin. These factors can be tested to guide therapy, but current evidence suggests that testing for inherited thrombophilia is not recommended in most inpatient settings. In the era of high value care, hypercoagulable testing for VTE creates a financial burden for the hospital and patients. We performed a retrospective chart review of hypercoagulable orders on VTE patients at our institution.

Methods: Institutional Review Board approval was obtained. A total of 287 adult patients admitted over a 3-month period with the diagnosis of VTE were included. Patients were identified via ICD-10 codes and data were collected from electronic medical records. Patient characteristics, provoked versus unprovoked VTE, and relative contraindications for hypercoagulability work-up were analyzed. Our primary outcome was to assess the appropriateness of thrombophilia testing in VTE patients based on screening guidelines. Our secondary outcome was to analyze the cost burden of ordering these tests.

Results: A total of 287 patients were included in our data analysis. Patient risk factors for VTE were malignancy, previous DVT, immobilization, surgery 3 months prior, and central line placement. Fifty-seven of 287 patients had at least one hypercoagulable test ordered during hospitalization which did not adhere to guidelines. Misuse of testing occurred during active thrombosis, active anticoagulation, presence of risk factors, first episode of VTE, and malignancy. The cost of ordering these 5 thrombophilia tests totaled over $\$ 40,000$.

Conclusion: In our study, numerous patients were tested without compliance to standard recommendations, which created financial and value-based burdens on our health care system. Increased awareness among clinicians is thus warranted to ensure high value care.

Keywords: venous thromboembolism, VTE, hypercoagulability, thrombophilia

\section{Introduction}

Venous thromboembolism (VTE) is an increasingly significant clinical event, with an annual incidence rate of approximately 1-2 per 1000 population. ${ }^{1}$ Along with the choice of treatment for VTE, clinicians must also plan the duration of treatment by identifying whether the incident was provoked or unprovoked by known risk factors for VTE, such as recent surgery, prolonged immobility, oral contraceptive use, and active cancer. ${ }^{2,3}$ Inherited risk factors include protein $\mathrm{C}$ deficiency, protein $\mathrm{S}$ deficiency, antithrombin deficiency, factor V Leiden (FVL) mutation, and prothrombin gene mutation G20210. ${ }^{4}$ Testing for inherited risk factors can be used for guidance on therapy; however, improper timing of these tests can affect 
thrombophilia results, leading to inappropriate anticoagulation therapy. The evidence currently available suggests that testing for inherited thrombophilia is not recommended in most clinical settings. In the era of high value care, it places a financial burden on both the hospital and its patients. ${ }^{4}$ Given this, we performed a retrospective review of hypercoagulable testing that was ordered on patients admitted for VTE at our institution, Jersey Shore University Medical Center (JSUMC).

\section{Methods}

After receiving Institutional Review Board (IRB) approval, a retrospective chart review was conducted for 287 adult patients (aged 18 years and older) admitted to JSUMC between May 2018 and August 2018. All clinical and laboratory data were compiled from the EMR. Our inclusion criteria included any adult patient presenting to the emergency department with a diagnosis of VTE. Patients were identified using ICD-10 codes for VTE.

Baseline clinical characteristics were gathered for each patient (Table 1), including gender, BMI, medical history, and family history of various thrombophilias. Furthermore, information was collected on the presence or absence of VTE risk factors, site of VTE, and thrombophilia test results. The patterns for ordering thrombophilia testing were reviewed for the following inherited conditions:

1. APC resistance/factor V Leiden mutation

2. Prothrombin gene mutation

3. Protein $\mathrm{S}$ deficiency

4. Protein $\mathrm{C}$ deficiency

5. Antithrombin deficiency

In the absence of definitive guidelines for thrombophilia testing, we reviewed the literature and, in conjunction with the JSUMC hematology-oncology department, created our own guidelines for this study. ${ }^{5-9}$ From this, we formulated contraindications for work-up (Table 2). Our guidelines for relative indications for hypercoagulability work-up are listed in Table 3. Our primary outcome was to assess the appropriateness of thrombophilia testing in patients with VTE in the inpatient setting based on published thrombophilia screening guidelines. Our secondary outcome was to analyze the cost burden of ordering these tests. In order to properly assess the financial impact of eliminating unwarranted thrombophilia testing, current market prices for thrombophilia tests were obtained from the inpatient laboratory department of the hospital. Simple statistical analysis was performed for this study. We considered ordering the work-up untimely if it was ordered for a patient with a provoked VTE, if ordered while the patient was on anticoagulation medication, or if ordered during an acute VTE, as detailed in Figure 1.

\section{Results}

Included in this review were 287 patients with a diagnosis of VTE. The following risk factors for VTE were analyzed in the selected patients: malignancy $(20.6 \%)$, previous DVT (19.9\%), immobilization (19.2\%), surgery in the past 3 months $(10.8 \%)$, and central line placement (1\%) (Table 1).

For 57 of the 287 patients, one or more type of hypercoagulable testing was performed (19.86\%). All 57 patients for whom the thrombophilia work-up was performed were found to have been unnecessarily tested as per our compiled guidelines (Table 2). Reasons for non-adherence were found to be: active thrombosis (57/57), active anticoagulation (47/ 57), presence of risk factors/provoked VTE (22/57), first episode of VTE (17/57), and malignancy (2/57) (Figure 2). We also evaluated the number of relative indications in these tested patients (Figure 3). These findings indirectly suggest the reasons for non-adherence to guidelines by the ordering physicians. Upon analyzing the financial burden related to improper testing, we calculated the total cost of ordering these five tests based on current market prices (Table 4). Based on current market prices, we found that the overall cost of ordering these five common tests - APC resistance/factor $\mathrm{V}$ Leiden mutation, prothrombin gene mutation, protein $\mathrm{S}$ deficiency, protein $\mathrm{C}$ deficiency, and antithrombin deficiency - totaled more than $\$ 40,000$.

\section{Discussion}

Thrombophilia is a condition that predisposes an individual to experience clot formation in the circulatory system. The etiology of thrombosis may be multifactorial, and the presence of a nidus causing thrombophilia is only one of many elements that may determine the risk of recurrence. Thrombophilia can be acquired or inherited. Inherited thrombophilia refers to conditions in which a genetic mutation affects the amount or function of a protein in the coagulation system. These factors include deficiencies of natural anticoagulants, such as protein $\mathrm{S}$, protein $\mathrm{C}$, antithrombin, and the two-point mutations - factor $\mathrm{V}$ Leiden and the prothrombin gene. ${ }^{9}$ Activated protein C resistance (APCR) due to FVL mutation is the most common hereditary thrombophilia among the Caucasian 
Table I Patient Demographics

\begin{tabular}{|c|c|c|}
\hline $\begin{array}{l}\text { Total } \\
\text { Patients }\end{array}$ & & 287 \\
\hline Age & & 63.7 years \\
\hline \multicolumn{3}{|l|}{ Gender } \\
\hline & $\begin{array}{l}\text { Male } \\
\text { Female }\end{array}$ & $\begin{array}{l}136(47.4 \%) \\
|5|(52.6 \%)\end{array}$ \\
\hline \multicolumn{3}{|l|}{ Race } \\
\hline & $\begin{array}{l}\text { White } \\
\text { Black } \\
\text { Asian } \\
\text { Other }\end{array}$ & $\begin{array}{l}234(81.5 \%) \\
80(27.9 \%) \\
9(3.1 \%) \\
40(14.0 \%)\end{array}$ \\
\hline BMI & & 29.71 \\
\hline \multicolumn{3}{|c|}{ Medical History } \\
\hline & $\begin{array}{l}\text { Immobilization } \\
\text { Hospitalization in last } 3 \text { months } \\
\text { Malignancy } \\
\text { Previous DVT } \\
\text { Prolonged travel } \\
\text { Chronic kidney disease } \\
\text { Atrial fibrillation } \\
\text { Inflammatory bowel disease } \\
\text { Liver disease } \\
\text { Heparin induced thrombocytopenia } \\
\text { Antiphospholipid syndrome } \\
\text { Cerebrovascular accident } \\
\text { Surgery in past } 3 \text { months } \\
\text { History of central line placement } \\
\text { Present pregnancy } \\
\text { Nephrotic syndrome } \\
\text { Congestive heart failure } \\
\text { PCOS } \\
\text { PNH } \\
\text { Warfarin induced skin necrosis } \\
\text { History of recurrent abortions } \\
\text { Substance abuse } \\
\text { Diabetes mellitus } \\
\text { Hypertension } \\
\text { Coronary artery disease } \\
\text { Chronic obstructive pulmonary } \\
\text { disease } \\
\text { Active malignancy }\end{array}$ & $\begin{array}{l}55 \\
80 \\
59 \\
57 \\
26 \\
27 \\
34 \\
3 \\
1 \\
3 \\
1 \\
14 \\
31 \\
6 \\
1 \\
1 \\
19 \\
0 \\
0 \\
0 \\
0 \\
14 \\
40 \\
136 \\
38 \\
21 \\
30\end{array}$ \\
\hline \multicolumn{3}{|c|}{ Family History } \\
\hline & $\begin{array}{l}\text { Factor } \mathrm{V} \text { mutation } \\
\text { Prothrombin gene mutation } \\
\text { Protein } \mathrm{S} \text { deficiency } \\
\text { Protein } \mathrm{C} \text { deficiency } \\
\text { Antithrombin III deficiency }\end{array}$ & $\begin{array}{l}4 \\
1 \\
0 \\
0 \\
0\end{array}$ \\
\hline
\end{tabular}

Table 2 Criteria for "No Adherence" to Guidelines for Inherited Thrombophilia

\begin{tabular}{|l|}
\hline $\begin{array}{l}\text { Provoked VTE (Presence of Major Transient Risk Factor Like } \\
\text { Surgery, Trauma or Prolonged Immobility) }\end{array}$ \\
\hline Ist episode of VTE, regardless of provoked v/s unprovoked \\
\hline Active malignancy \\
\hline Acute/active VTE \\
\hline Active VTE treatment/Anticoagulation \\
\hline
\end{tabular}

Table 3 Relative Indications for Hypercoagulability Work-Up

\begin{tabular}{|l|}
\hline Recurrent VTE/Prior History of VTE \\
\hline Family history of hypercoagulable state \\
\hline VTE at unusual sites \\
\hline VTE at age $<45$ years \\
\hline
\end{tabular}

population. ${ }^{10}$ Acquired thrombophilia includes antiphospholipid syndrome (APS), among other autoimmune disorders such as Behcet's disease. ${ }^{11}$ The primary instance in which testing for thrombophilia leads to a change in treatment is the presence of APS, for which warfarin is recommended rather than a direct oral anticoagulant (DOAC). ${ }^{12}$ The presence of APS is furthermore distinguished from the significant determination of provoked versus unprovoked VTEs.

Provoked VTEs have a much lower recurrence rate, estimated to be less than $1 \%$ annually, than unprovoked VTEs, which have a recurrence rate ranging from $5-27 \% .{ }^{13}$ Sometimes, clinicians will obtain thrombophilia work-ups by citing their possible use as a risk stratification model for determining duration of anticoagulation. However, the literature suggests that other models may be more beneficial in this situation. For instance, in a multicenter prospective cohort study, Rodger et al analyzed patients with unprovoked VTE and their recurrence rates. The study found that men have a higher recurrence rate than women, estimated to be $13.7 \%$ annually. Yet, for women, the recurrence rate varied depending on the following characteristics: hyperpigmentation, edema/redness of the lower extremities, 


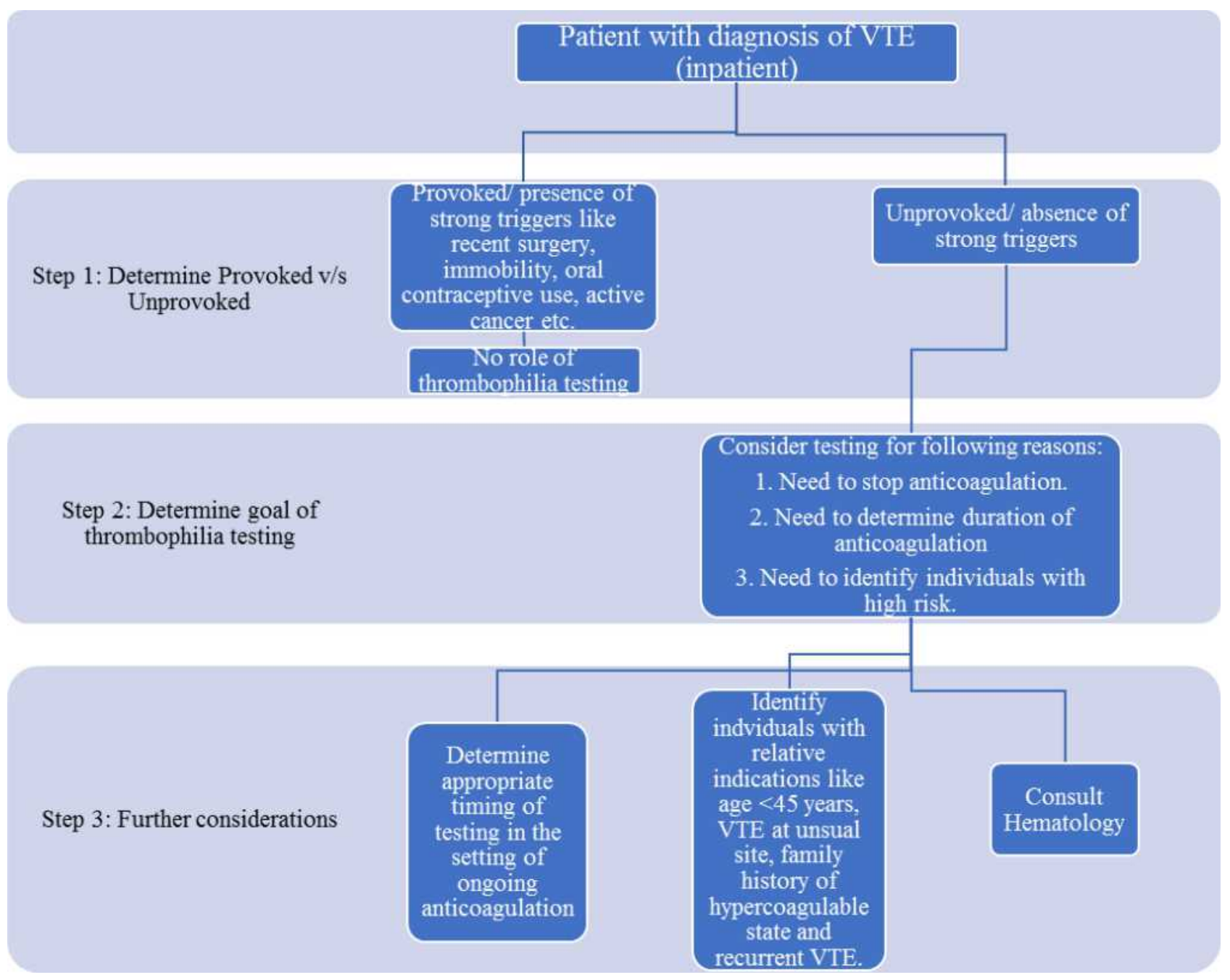

Figure I Suggested algorithm for determining the need for a hypercoagulability work-up.

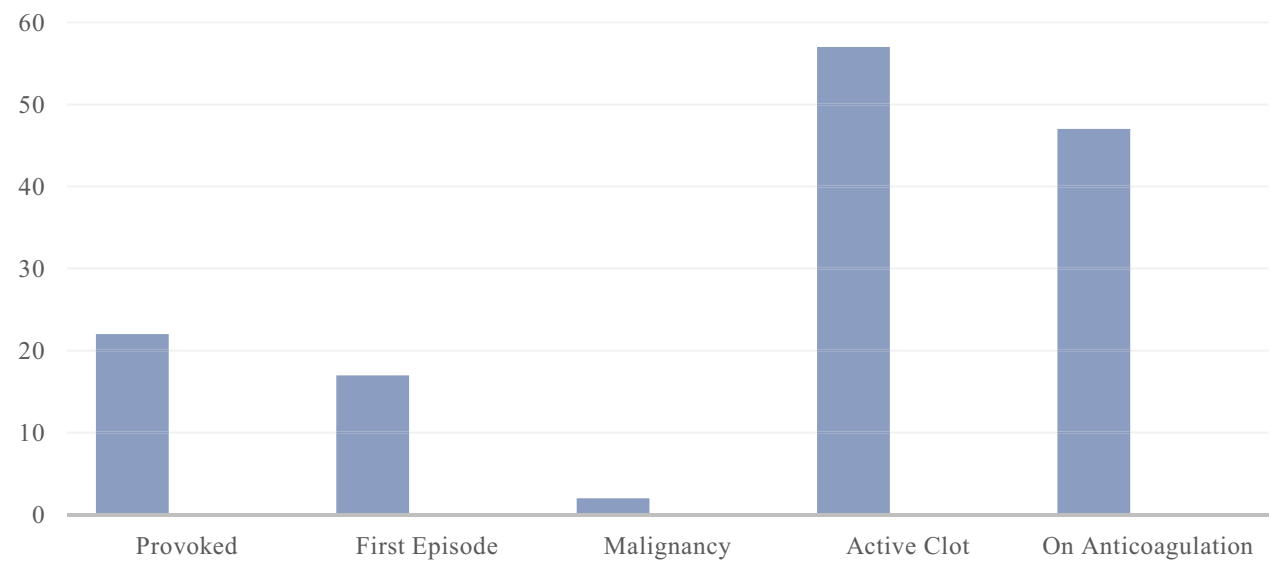

Figure 2 Analysis of why the hypercoagulability work-up was ordered unnecessarily. 


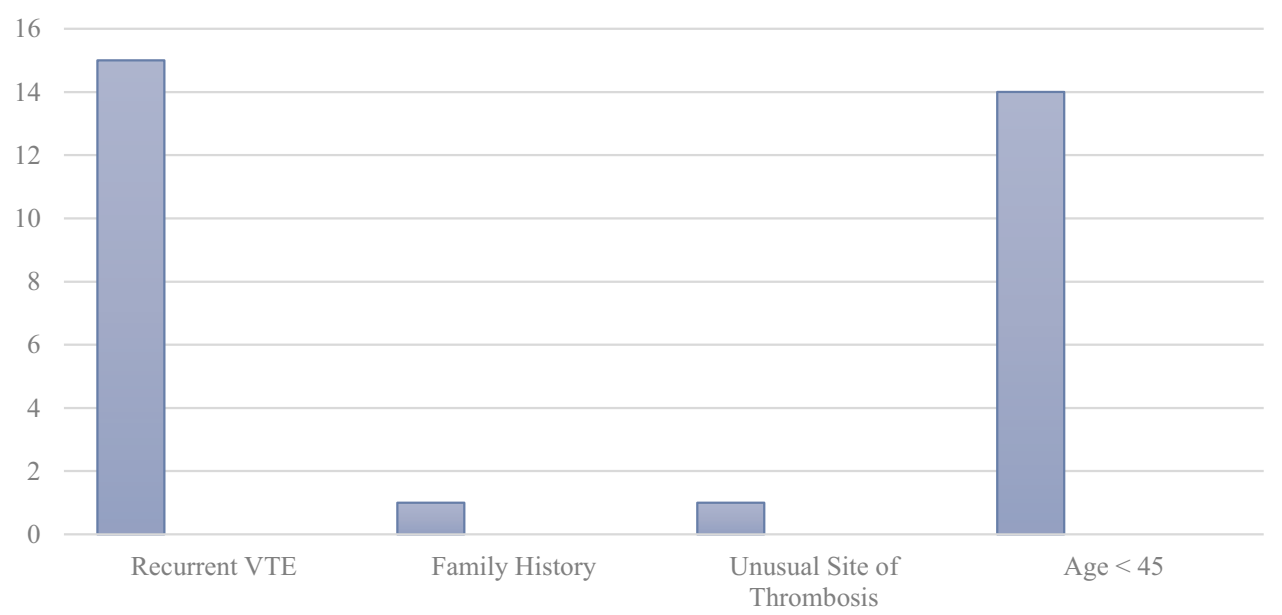

Figure 3 Analysis of relative indications present in patients who received thrombophilia work-up.

D-dimer $>250$, BMI $>30$, and age $>65$ years. Women with $0-1$ of these characteristics had a $1.6 \%$ recurrence rate, whereas women with 2 or more traits had a recurrence rate of $14.1 \%$, like men. ${ }^{13}$ The authors concluded that women with unprovoked VTE and 0-1 risk characteristics as listed above could discontinue anticoagulation after treatment of their acute VTE.

There are differing opinions regarding anticoagulation and thrombophilia, since the literature is unclear if they confer a higher risk of recurrence. ${ }^{11}$ Some, such as Stevens et al, recommended not performing thrombophilia testing following an episode of provoked VTE, as a positive test is not enough to determine the duration of anticoagulation and may subject patients to otherwise avoidable bleeding risks. $^{8}$ They also reported that thrombophilia testing should not be performed in patients after a single episode of unprovoked VTE because a negative result is not enough to stop anticoagulation in a patient with low bleeding risk and willingness to continue therapy. Females with a personal history of unprovoked VTE or estrogen/ pregnancy-related VTE also carry an indication for prophylaxis and are unlikely to benefit from testing.

Others, such as Connors et al, recommended thrombophilia testing at the completion of anticoagulation therapy for provoked VTE. ${ }^{9}$ Conversely, for unprovoked VTE, they recommended testing after the event if cessation of therapy is being considered, and if the test would change management strategy. Current medications and the presence of an active VTE should be accounted for. Several reports in the literature recommend waiting 6 weeks postacute VTE as this entity may decrease protein $\mathrm{C}$, protein $\mathrm{S}$, and factor VIII, thus interfering with test results. ${ }^{14}$ Regarding timing of the testing, Connors et al recommend waiting until 2 weeks after vitamin $\mathrm{K}$ antagonists (VKA) are stopped, 2 days after a DOAC is stopped, and 1 day after unfractionated heparin or low-molecular-weight heparin is stopped. ${ }^{9,10}$ Heparin products such as UFH and LMWH interfere with antithrombin levels. Pruthi et al noted that a DOAC may result in a false positive APCR. VKAs decrease protein $\mathrm{S}$ and protein $\mathrm{C}$ levels and

Table 4 Cost Analysis

\begin{tabular}{|l|l|l|l|}
\hline Type of Test & No. of Times Ordered & Current Price of Test & Total Cost \\
\hline APC resistance/Factor V Leiden mutation & 43 & $\$ 241$ & $\$ 10,363$ \\
\hline Prothrombin gene mutation & 13 & $\$ 237$ & $\$ 3081$ \\
\hline Protein S deficiency & 37 & $\$ 180$ & $\$ 6660$ \\
\hline Protein C deficiency & 36 & $\$ 231$ & $\$ 8316$ \\
\hline Antithrombin deficiency & 36 & $\$ 226$ & $\$ 8136$ \\
\hline & & & $\$ 36,556$ \\
\hline
\end{tabular}


thus may also yield false positive or indeterminate assay results. ${ }^{15}$ Various studies in the past have found that diagnosing a heritable thrombophilia does not typically predict recurrence and that a significant risk of bleeding does not justify extending the duration of anticoagulation. ${ }^{16-18}$

Official guidelines, such as those of the "Choosing Wisely" campaign of the American Society of Hematology (ASH), recommend that patients diagnosed with VTE do not undergo thrombophilia testing in the context of major transient VTE risk factors such as surgery, trauma, or prolonged immobility. ${ }^{5}$ The rationale for this recommendation is that testing will not influence the duration or intensity of treatment. ASH thus recommends guidance from an expert in the field regarding testing for thrombophilia.

In 2010, the British Society for Haematology and the British Committee for Standards in Haematology published recommendations for testing heritable thrombophilia. ${ }^{6}$ They recommended testing of selected patients, such as those presenting with VTE at an early age (under 40 years of age) or those with a significant family history of thrombosis, defined as more than two family members. Other groups they reported as possibly benefiting from testing include children with purpura fulminans and pregnant women at risk for VTE. Relevant grade I recommendations from the study include the following: ${ }^{6}$

1. Initiation and intensity of anticoagulation therapy following a diagnosis of acute VTE should be the same in patients with or without heritable thrombophilia

2. Indiscriminate testing for heritable thrombophilia in unselected patients presenting with a first episode of VTE is not indicated

3. Decisions regarding the duration of anticoagulation, ie short-term versus lifelong, should be decided based on whether the VTE was provoked, along with other risk factors including a known history of heritable thrombophilia

4. Case findings of asymptomatic relatives with high risk thrombophilia deficiencies, such as protein $\mathrm{C}$, protein $\mathrm{S}$, and antithrombin deficiencies, should be considered in selected patients with a significant family history of thrombosis

5. If a first-degree relative with VTE has not been tested, then suggest that female patients consider an alternative means of contraception to oral contraceptive pills

6. Testing for heritable thrombophilia is not indicated with arterial thrombosis

As per the National Institute for Health and Clinical Excellence (NICE) guidelines, thrombophilia testing may be considered for individuals when considering discontinuation of anticoagulation following an unprovoked VTE. ${ }^{7}$ For unprovoked events, the decision whether to continue or discontinue anticoagulation should be made 3 months postVTE episode. Some literature does suggest that hereditary thrombophilias have a higher risk of recurrence, estimated to be elevated by a factor ranging from 4 to $30,{ }^{19}$ however, the need for a hypercoagulability work-up should ultimately be determined by a hematologist-oncologist.

The available evidence suggests that testing for inherited thrombophilia is not recommended in most clinical settings. The testing of hypercoagulability requires a planned and thoughtful approach and may require consulting an expert in the field of hematologyoncology. Clinicians should avoid ordering thrombophilia testing in hospitalized patients for the following reasons: (1) many tests are inaccurate in the setting of acute VTE and ongoing anticoagulation; (2) results will not influence management; (3) it is a cost burden to both patients and hospitals; and (4) a positive test result may lead to patient anxiety and an improperly prolonged course of anticoagulation. Based on the results of our study and literature review, we created an algorithm by which physicians can more effectively decide when to perform thrombophilia testing (Figure 1). We aim to conduct a 5-year follow-up retrospective chart review at our institution after educating our clinicians on how to use the devised thrombophilia algorithm. We plan to analyze a similar cohort of patients using similar ICD-10 codes and thereafter analyze adherence to testing guidelines based on our institutional algorithm along with its financial impact. This additional retrospective study will assess improvement in ordering practices at our institution for the betterment of high value patient care.

This study was limited by its nature as a retrospective, single center study with a relatively small sample size. The information was obtained via chart review of patients identified with ICD-10 codes, but it is possible there may have been patients with VTE who were not identified and therefore not included. It is also possible that patients who did not follow-up at our center were later diagnosed with 
malignancy and thus the provoked VTE rate may have been higher than reported in our study. Additionally, no hospital-based protocol was followed.

\section{Conclusion}

Our study demonstrates that there is a low degree of adherence to currently available thrombophilia testing recommendations in our institutional inpatient setting, which is an ineffective use of resources and can cause an unnecessary financial burden. An increased awareness among clinicians is thus warranted when ordering hypercoagulable work-up to adopt high value care and costeffective testing. Additionally, there are other proposed algorithms for determining length of anticoagulation, which warrant clinicians' attention. We furthermore propose an algorithm by which we aim to guide and assess the appropriateness of thrombophilia testing at our institution.

\section{Statement of Ethics}

Ethical approval to conduct this study was obtained from the Institutional Review Board (IRB). This study was approved and issued under the Federal Wide Assurance with the Office for Human Research Protections. Patient data acquired was anonymized.

\section{Consent for Publication}

An informed consent waiver was approved for this study by the IRB.

\section{Author Contributions}

All authors made substantial contributions to conception and design, acquisition of data, or analysis and interpretation of data; took part in drafting the article or revising it critically for important intellectual content; agreed on the journal to which the article will be submitted; gave final approval of the version to be published; and agree to be accountable for all aspects of the work.

\section{Funding}

This project was not supported by any grants or funding agencies.

\section{Disclosure}

Dr Michael J Levitt is a member of the Speakers' Bureau for Amgen, Takeda, and GlaxoSmithKline, outside the submitted work. The authors declare that there is no other conflict of interest regarding the publication of this paper.

\section{References}

1. Naess IA, Christiansen SC, Romundstad P, et al. Incidence and mortality of venous thrombosis: a population-based study. J Thromb Haemost. 2007;5(4):692-699. doi:10.1111/j.1538-7836.2007.02450.x PMID: 17367492.

2. Kearon C, Akl EA, Ornelas J, et al. Antithrombotic therapy for VTE disease: CHEST guideline and expert panel Report [published correction appears in Chest. 2016 Oct;150(4):988]. Chest. 2016;149 (2):315-352. doi:10.1016/j.chest.2015.11.026

3. Pollak AW, McBane RD. Succinct review of the new VTE prevention and management guidelines. Mayo Clin Proc. 2014;89(3):394-408. doi:10.1016/j.mayocp.2013.11.015

4. Middeldorp S. Inherited thrombophilia: a double-edged sword. Hematology Am Soc Hematol Educ Program. 2016;2016(1):1-9. doi:10.1182/asheducation-2016.1.1

5. Hicks LK, Bering H, Carson KR, et al. The ASH Choosing Wisely ${ }^{\circledR}$ campaign: five hematologic tests and treatments to question. Hematology Am Soc Hematol Educ Program. 2013;2013(1):9-14. doi:10.1182/asheducation-2013.1.9

6. Baglin T, Gray E, Greaves M, et al. Clinical guidelines for testing for heritable thrombophilia. Br J Haematol. 2010;149(2):209-220. doi:10.1111/j.1365-2141.2009.08022.x

7. Howard LS, Hughes RJ. NICE guideline: management of venous thromboembolic diseases and role of thrombophilia testing. Thorax. 2013;68(4):391-393. doi:10.1136/thoraxjnl-2012-202376

8. Stevens SM, Woller SC, Bauer KA, et al. Guidance for the evaluation and treatment of hereditary and acquired thrombophilia. $J$ Thromb Thrombolysis. 2016;41(1):154-164. doi:10.1007/s11239-015-1316-1

9. Connors JM, Longo DL. Thrombophilia testing and venous thrombosis. N Engl J Med. 2017;377(12):1177-1187. doi:10.1056/ NEJMra1700365

10. Singh D, Natarajan A, Nand S, Mai HP. Genetics of hypercoagulable and hypocoagulable states. Neurosurg Clin N Am. 2018;29 (4):493-501. doi:10.1016/j.nec.2018.06.002

11. Rybstein MD, DeSancho MT. Hypercoagulable states and thrombophilias: risks relating to recurrent venous thromboembolism. Semin Intervent Radiol. 2018;35(2):99-104. doi:10.1055/s-0038-1642037

12. Garcia D, Erkan D. Diagnosis and management of the antiphospholipid syndrome. $N$ Engl $J$ Med. 2018;378(21):2010-2021. doi:10.1056/NEJMra1705454

13. Rodger MA, Kahn SR, Wells PS, et al. Identifying unprovoked thromboembolism patients at low risk for recurrence who can discontinue anticoagulant therapy. CMAJ. 2008;179(5):417-426. doi:10.1503/cmaj.080493

14. Heit JA. Thrombophilia: common questions on laboratory assessment and management. Hematology Am Soc Hematol Educ Program. 2007;2007(1):127-135. doi:10.1182/asheducation-2007.1.127

15. Pruthi RK. Optimal utilization of thrombophilia testing. Int $J$ Lab Hematol. 2017;39(Suppl 1):104-110. doi:10.1111/ijlh.12672

16. Baglin T, Luddington R, Brown K, Baglin C. Incidence of recurrent venous thromboembolism in relation to clinical and thrombophilic risk factors: prospective cohort study. Lancet. 2003;362 (9383):523-526. doi:10.1016/S0140-6736(03)14111-6

17. Christiansen SC, Cannegieter SC, Koster T, Vandenbroucke JP, Rosendaal FR. Thrombophilia, clinical factors, and recurrent venous thrombotic events. JAMA. 2005;293(19):2352-2361. doi:10.1001/ jama.293.19.2352

18. Ho WK, Hankey GJ, Quinlan DJ, Eikelboom JW. Risk of recurrent venous thromboembolism in patients with common thrombophilia: a systematic review. Arch Intern Med. 2006;166(7):729-736. doi:10.1001/archinte.166.7.729

19. Campello E, Spiezia L, Adamo A, Simioni P. Thrombophilia, risk factors and prevention. Expert Rev Hematol. 2019;12(3):147-158. doi:10.1080/17474086.2019.1583555 


\section{Publish your work in this journal}

The Journal of Blood Medicine is an international, peer-reviewed, open access, online journal publishing laboratory, experimental and clinical aspects of all aspect pertaining to blood based medicine including but not limited to: Transfusion Medicine; Blood collection, Donor issues, Transmittable diseases, and Blood banking logistics; Immunohematology; Artificial and alternative blood based therapeutics; Hematology; Biotechnology/nanotechnology of blood related medicine; Legal aspects of blood medicine; Historical perspectives. The manuscript management system is completely online and includes a very quick and fair peer-review system. Visit http://www.dovepress.com/testimonials.php to read real quotes from published authors. 